\title{
BALANÇO HÍDRICO CLIMATOLÓGICO E CLASSIFICAÇÃO CLIMÁTICA PARA O MUNICÍPIO DE PARANAVAÍ, PARANÁ
}

\author{
CLIMATIC WATER BALANCE AND CLIMATIC CLASSIFICATION FOR PARANAVAÍ \\ MUNICIPATILITY, PARANÁ \& \\ BALANCE HÍDRICO CLIMÁTICO Y CLASSIFICACIÓN CLIMÁTICA PARA EL \\ MUNICIPALIDAD DE PARANAVAÍ, PARANÁ \&
}

Recebido em: 07/10/2021 - Aprovado em: 14/10/2021 - Publicado em: 18/10/2021

http://dx.doi.org/10.18011/bioeng2021v15n3p367-380

Allan Remor Lopes' (allanremorlopes@gmail.com)

Marcelo Dotto² (marcelo.dotto@unisep.edu.br)

Elouize Xavier² (elouize@unisep.edu.br)

Camila Moreno Giarola3 ${ }^{3}$ (camila.giarola@edu.unipar.br)

Kelli Pirola ${ }^{4}$ (kelli_pirola1@hotmail.com)

\footnotetext{
1 Universidade Estadual do Oeste do Paraná. Cascavel, PR, Brasil.

${ }^{2}$ Centro Universitário UNISEP. Dois Vizinhos, PR, Brasil.

${ }^{3}$ Universidade Paranaense. Umuarama, PR, Brasil.

${ }^{4}$ Universidade Tecnológica Federal do Paraná. Pato Branco, PR, Brasil.
}

\section{RESUMO}

A compreensão das condições climáticas do município de Paranavaí deve ser considerada devido à sua importância no cenário agrícola nacional. Nesse estudo, calculou-se o balanço hídrico climatológico (BHC) e determinado a cllassificação climática pelo método de Thornthwaite e Mather para o município de Paranavaí, Paraná. Foram utilizados dados de uma série temporal de 1975 a 2018, e adotado o valor de $100 \mathrm{~mm}$ para a capacidade de água disponível (CAD). Paranavaí apresentou uma média anual de precipitação de 1523,8 mm, e 1090,62 de evapotranspiração potencial (ETp). O município apresentou um mês de deficiência hídrica (agosto) e onze meses de excesso de água (setembro a julho). Em relação a classificação climática, foi classificado como $\mathrm{C}_{1} \mathrm{dA} \mathrm{A}^{\prime} \mathrm{a}^{\prime}$, caracterizado como um clima mesotérmico com pequena ou nenhuma deficiência hídrica.

Keywords: Deficiência hídrica. Evapotranspiração. Precipitação. Irrigação. 


\section{INTRODUÇÃO}

Devido ao aumento populacional e consequente elevação da demanda alimentar, é visível a preocupação da humanidade nos últimos tempos, em relação à disponibilidade de água (SALES et al., 2018).

O município de Paranavaí destaca-se no cenário paranaense pela sua produção de e mandioca (1960 ha de área plantada), sendo considerado o maior polo de produção do Paraná e $2^{\circ}$ maior do Brasil, e pela produção de cana-de-açúcar (15184 ha de área plantada) (IBGE, 2020). O conhecimento das características hidrológicas de uma região é fundamental para sua produção agrícola, pois, permite estabelecer os períodos de disponibilidade e escassez hídrica (OLIVEIRA, 2019).

Nesse sentido, o conhecimento do balanço hídrico de uma determinada região permite identificar potencialidades e fragilidades para a produção agrícola, pois a produtividade agrícola é dependente da disponibilidade hídrica da região produtora, e para a obtenção do máximo rendimento, é necessária a observação dos fatores agrometeorológicos em todas as fases do desenvolvimento da cultura. Além de identificar as aptidões agrícolas, a estimativa do balanço hídrico contribui para planejamento da agricultura irrigada (PASSOS et al., 2016).

O balanço hídrico é obtido computando a demanda e a disponibilidade hídrica por meio de precipitação pluviométrica, evapotranspiração potencial, armazenamento de água no solo, deficiência hídrica e excedente hídrico. A partir desse método é possível conhecer o regime hídrico de uma região de forma simples e prática (MATOS et al., 2020).

Os valores resultantes do cálculo do balanço hídrico climatológico $(\mathrm{BHC})$, também possibilitam realizar a classificação climática, já que os dados necessários são justamente os determinados na resolução do balanço hídrico (DANTAS et al., 2007).

Existem diversos sistemas de classificação climática, dentre eles destaca-se o método de Thornthwaite e Mather (1955), que utiliza métodos índices definidos com base no BHC (SILVA et al., 2014), e se constitui uma ferramenta importante visando o monitoramento do armazenamento de água no solo, utilizada como instrumento de planejamento para o manejo de culturas agrícolas (PASSOS et al., 2017). Para Da Silva \& Nascimento (2020), o BHC caracteriza épocas mais propicias para a prática da agricultura. Neste contexto, conhecer as condições climáticas é de grande valor para um planejamento agrícola adequado. 
Diante disso, o presente trabalho teve o objetivo de analisar a disponibilidade hídrica através do balanço hídrico climatológico e realizar a classificação climática para o município de Paranavaí, Paraná.

\section{MATERIAIS E MÉTODOS}

A área de estudo compreende o município de Paranavaí, que está localizado na região Noroeste do Paraná, e apresenta uma área de 1202,266 km². Sua localização tem as seguintes coordenadas: Latitude $23^{\circ} 4^{\prime} 26^{\prime \prime}$ Sul e Longitude $52^{\circ} 27^{\prime} 55^{\prime \prime}$ Oeste (Figura 1).

Figura 1 - Localização do município de Paranavaí, Paraná.

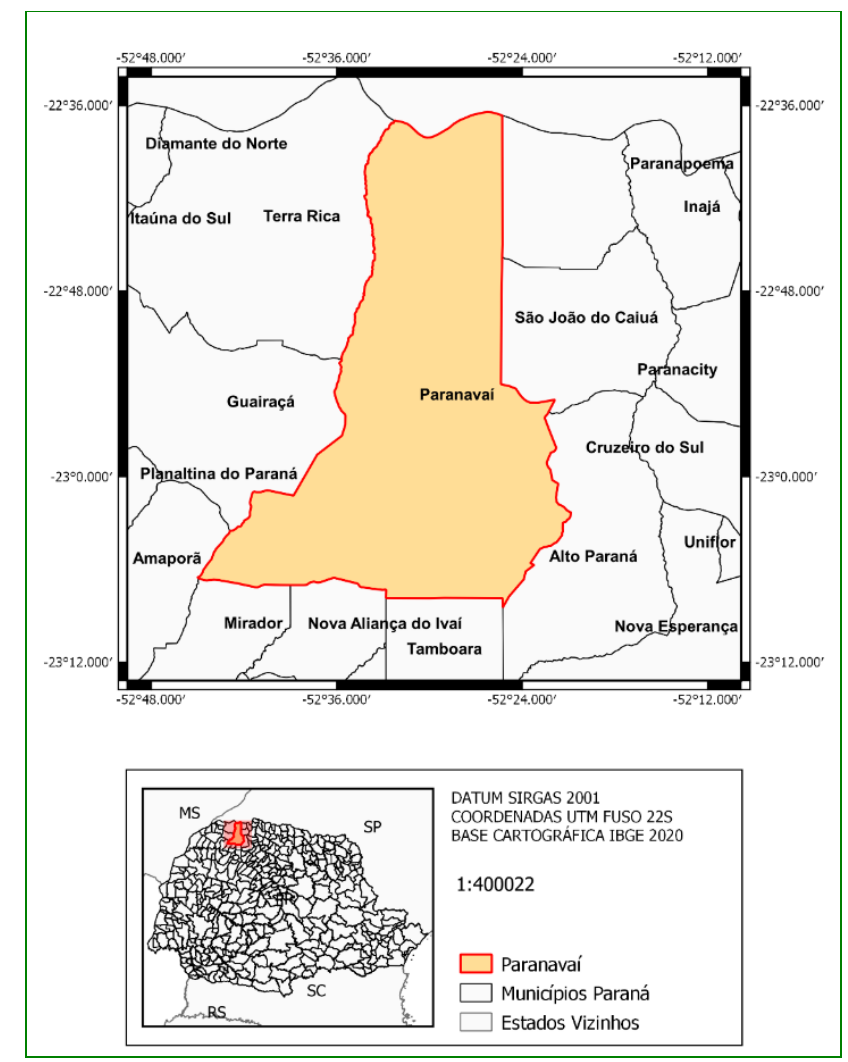

Fonte: Autor (2021).

Os dados foram obtidos a partir da estação meteorológica Criação Estado, do Instituto Agronômico do Paraná (IAPAR), código 02352017, que estão disponibilizados no Instituto Água e Terra (IAT, 2021). A estação localiza-se nas coordenadas de 2304' 59" de latitude e $52^{\circ} 25^{\prime} 59^{\prime \prime}$ de longitude e altitude de $480 \mathrm{~m}$.

Foram utilizados dados mensais de temperatura e precipitação, compreendendo uma série histórica de 43 anos, de 1975 à 2018, conforme recomendação da Organização Meteorológica Mundial (WMO, 1989), a qual relata que são necessários pelo menos 30 
anos de dados climáticos para que se tenha maior confiabilidade na caracterização climática de uma localidade (BLAIN; BRUNINI, 2007). O cálculo do BHC foi realizado através de planilhas eletrônicas no Microsoft Excel.

A classificação climática foi estimada a partir do método de Thornthwaite e Mather (1955), que utiliza os dados de excesso e deficiência hídrica anual obtida do BHC para encontrar os Índices: Hídrico (Ih), Aridez (la) e Umidade (lu), de acordo com as equações 1, 2 e 3 :

$$
\begin{aligned}
& \mathrm{Ih}=\left(\frac{\mathrm{EXC}}{\mathrm{ETP}}\right) \times 100 \\
& \mathrm{la}=\left(\frac{\mathrm{DEF}}{\mathrm{ETP}}\right) \times 100 \\
& \mathrm{lu}=(\mathrm{Ih}-0,6) \times \mathrm{la}
\end{aligned}
$$

Em que: Ih = Índice hídrico (\%); la = índice de aridez (\%); lu = índice de umidade (\%).

A partir dos índices obtidos, foram determinadas a primeira e a segunda-chave para a classificação climática (Tabelas 1 e 2).

Tabela 1. Chave inicial da classificação climática segundo Thornthwaite, baseado nos índices de umidade.

\begin{tabular}{cc}
\hline Tipos Climáticos & Índice de Umidade (lu) \\
\hline A - Super úmido & $100 \leq \mathrm{lu}$ \\
B4 - Úmido & $80 \leq \mathrm{lu}<100$ \\
B3 - Úmido & $60 \leq \mathrm{lu}<80$ \\
B2 - Úmido & $40 \leq \mathrm{lu}<60$ \\
B1 - Úmido & $20 \leq \mathrm{lu}<40$ \\
C2 - Sub-úmido & $00 \leq \mathrm{lu}<20$ \\
C1 - Sub-úmido seco & $-33,33 \leq \mathrm{lu}<00$ \\
D - Semi-árido & $-66,7 \leq \mathrm{lu}<-33,33$ \\
E - Árido & $-100 \leq \mathrm{lu}<-66,7$ \\
\hline
\end{tabular}


Tabela 2. Segundo-chave-subtipos climáticos, segundo Thornthwaite, baseados nos índices de aridez e umidade.

\begin{tabular}{|c|c|c|c|}
\hline $\begin{array}{c}\text { Climas úmidos (A, B4, } \\
\text { B3, B2, B1 e C2) }\end{array}$ & Índice de aridez (la) & $\begin{array}{c}\text { Climas secos (C1, D e } \\
\text { E) }\end{array}$ & Índice de umidade (lu) \\
\hline$r$ - pequena ou & $0-16,7$ & $\mathrm{~d}$ - pequeno ou & $0-10$ \\
\hline nenhuma deficiência & & nenhum excesso de & \\
\hline de água & & água & \\
\hline s - moderada & $16,7-33,33$ & s - moderado excesso & $10-20$ \\
\hline deficiência no verão & & de inverno & \\
\hline w - moderada & $16,7-33,33$ & w - moderado & $10-20$ \\
\hline deficiência no inverno & & excesso de verão & \\
\hline s2 - grande & $>33,33$ & s2 - largo excesso de & 20 \\
\hline deficiência no verão & & inverno & \\
\hline w2 - grande & $>33,33$ & w2 - largo excesso de & 20 \\
\hline deficiência no inverno & & verão & \\
\hline
\end{tabular}

A partir do BHC, com os dados de precipitação foram obtidos a terceira e quarta chave para classificação climática (Tabelas 3 e 4).

Tabela 3. Terceira chave de classificação climática segundo Thornthwaite, baseado no índice térmico (ETo anual).

\begin{tabular}{cc}
\hline Tipo climático & Índice térmico (ETo anual) \\
\hline A' - megatérmico & $\geq 1140$ \\
B'4 - mesotérmico & $997-1140$ \\
B'3 - mesotérmico & $855-997$ \\
B'2 - mesotérmico & $712-855$ \\
B'1 - mesotérmico & $570-712$ \\
C'2 - microtérmico & $427-570$ \\
C'1 - microtérmico & $285-427$ \\
D' - tundra & $142-285$ \\
E' - gelo perpétuo & $<142$ \\
\hline
\end{tabular}


Tabela 4. Quarta chave de classificação climática segundo Thornthwaite, baseado na relação entre ETP de verão (ETPv) e anual (ETP).

\begin{tabular}{cc}
\hline Subtipo climático & Concentração da ETP no verão (\%) \\
\hline a' & $<48 \%$ \\
b'4 & $48-51,9$ \\
b'3 & $51,9-56,3$ \\
b'2 & $56,3-61,6$ \\
b'1 & $61,6-68$ \\
c'2 & $68-76,3$ \\
c'1 & $76,3-88$ \\
d' & $>88$
\end{tabular}

\section{RESULTADOS E DISCUSSÃO}

O balanço hídrico climatológico (BHC) para o município de Paranavaí-PR, está apresentado na Tabela 5.

Tabela 5. Balanço hídrico climatológico pelo método de Thornthwaite e Mather (1955), para o município de Paranavaí, Paraná, no período de 1975 à 2018.

\begin{tabular}{ccccccccccc}
\hline Mês & T. $\left({ }^{\circ} \mathrm{C}\right)$ & $\begin{array}{c}\mathrm{P} . \\
(\mathrm{mm})\end{array}$ & $\begin{array}{c}\mathrm{ETP} \\
(\mathrm{mm})\end{array}$ & $\begin{array}{c}\mathrm{P}- \\
\mathrm{ETP} \\
(\mathrm{mm})\end{array}$ & $\begin{array}{c}\text { NEG. } \\
\text { AC. } \\
(\mathrm{mm})\end{array}$ & $\begin{array}{c}\text { ARM. } \\
(\mathrm{mm})\end{array}$ & $\begin{array}{c}\text { ALT. } \\
(\mathrm{mm})\end{array}$ & $\begin{array}{c}\text { ETR } \\
(\mathrm{mm})\end{array}$ & $\begin{array}{c}\text { DEF. } \\
(\mathrm{mm})\end{array}$ & $\begin{array}{c}\text { EXC. } \\
(\mathrm{mm})\end{array}$ \\
\hline Jan. & 25,1 & 189,1 & 137,08 & 52 & 0 & 100 & 0 & 137,1 & 0 & 52 \\
Fev. & 24,9 & 171,2 & 118,07 & 53,1 & 0 & 100 & 0 & 118,1 & 0 & 53,1 \\
Mar. & 24,4 & 128,7 & 118,86 & 9,8 & 0 & 100 & 0 & 118,9 & 0 & 9,8 \\
Abr. & 22,2 & 100,3 & 85,38 & 14,9 & 0 & 100 & 0 & 85,4 & 0 & 14,9 \\
Mai. & 19,5 & 116,6 & 60,01 & 56,6 & 0 & 100 & 0 & 60 & 0 & 56,6 \\
Jun. & 17,9 & 97,2 & 44,8 & 52,4 & 0 & 100 & 0 & 44,8 & 0 & 52,4 \\
Jul. & 18,1 & 67,2 & 47,3 & 19,9 & 0 & 100 & 0 & 47,3 & 0 & 19,9 \\
Ago. & 19,9 & 58,4 & 62,12 & $-3,7$ & $-3,7$ & 96,34 & $-3,7$ & 62,1 & 0,1 & 0 \\
Set. & 20,7 & 126,1 & 70,18 & 55,9 & 0 & 100 & 3,7 & 70,2 & 0 & 52,3 \\
Out. & 22,9 & 158,7 & 99,26 & 59,4 & 0 & 100 & 0 & 99,3 & 0 & 59,4 \\
Nov. & 24,1 & 139,6 & 115,23 & 24,4 & 0 & 100 & 0 & 115,2 & 0 & 24,4 \\
Dez. & 24,8 & 170,7 & 132,34 & 38,4 & 0 & 100 & 0 & 132,3 & 0 & 38,4 \\
\hline Total & 264,5 & 1523,8 & 1090,62 & 433,2 & & 1196,34 & 0 & 1090,6 & 0,1 & 433,2 \\
Média & 22 & 127 & 90,89 & 36,1 & & 99,7 & & 90,9 & 0 & 36,1 \\
\hline
\end{tabular}

T - Temperatura do ar; P - Precipitação; ETP - Evapotranspiração potencial; P - ETP - Quantidade de água que permanece no solo; NEG. AC. - Negativo acumulado; ARM - Armazenamento de água no solo;

ALT - ARMatual - ARManterior; ETR - Evapotranspiração real; DEF - Deficiência hídrica e EXC Excedente hídrico. Fonte: Do autor (2021).

Por meio dos dados obtidos verificou-se uma temperatura média anual de $22{ }^{\circ} \mathrm{C}$, com mínima de $17,9{ }^{\circ} \mathrm{C}$ em junho e máxima de $25,1{ }^{\circ} \mathrm{C}$ em janeiro (Tabela 5 ).

A precipitação pluviométrica anual foi de $1523,8 \mathrm{~mm}$, com distribuição irregular ao longo do ano, com mínima de 58,4 mm no mês de agosto e máxima de $189,1 \mathrm{~mm}$ no mês de janeiro. Foi possível observar uma estação seca bem definida que ocorre entre os meses 

de junho à agosto, representando apenas 14,6\% da precipitação anual (Tabela 5). Parreira et al. (2019) ao realizarem o balanço hídrico para Rio Verde, Goiás, também obtiveram como período mais crítico o mês de agosto.

A evapotranspiração potencial (ETP) obteve uma taxa anual de 1090,1 mm, com variação mínima de 44,8 mm no mês de junho e máxima de 137,08 mm no mês de janeiro (Tabela 5), compreendendo 12,5\% da evapotranspiração anual.

Através da Figura 2, verifica-se que ocorre uma tendência de queda de precipitação de janeiro (189,1 $\mathrm{mm}$ ) até agosto, onde atinge seu valor mínimo (58,4 mm). Além de atingir o valor mínimo em agosto, também é possível notar que a ETP $(62,12 \mathrm{~mm})$ é maior que a precipitação.

Figura 2 - Níveis de precipitação, evapotranspiração (ETP) e evapotranspiração de referência (ETR) do município de Paranavaí, Paraná. Método de Thornthwaite \& Mather (1955). Período: 1975-2018.

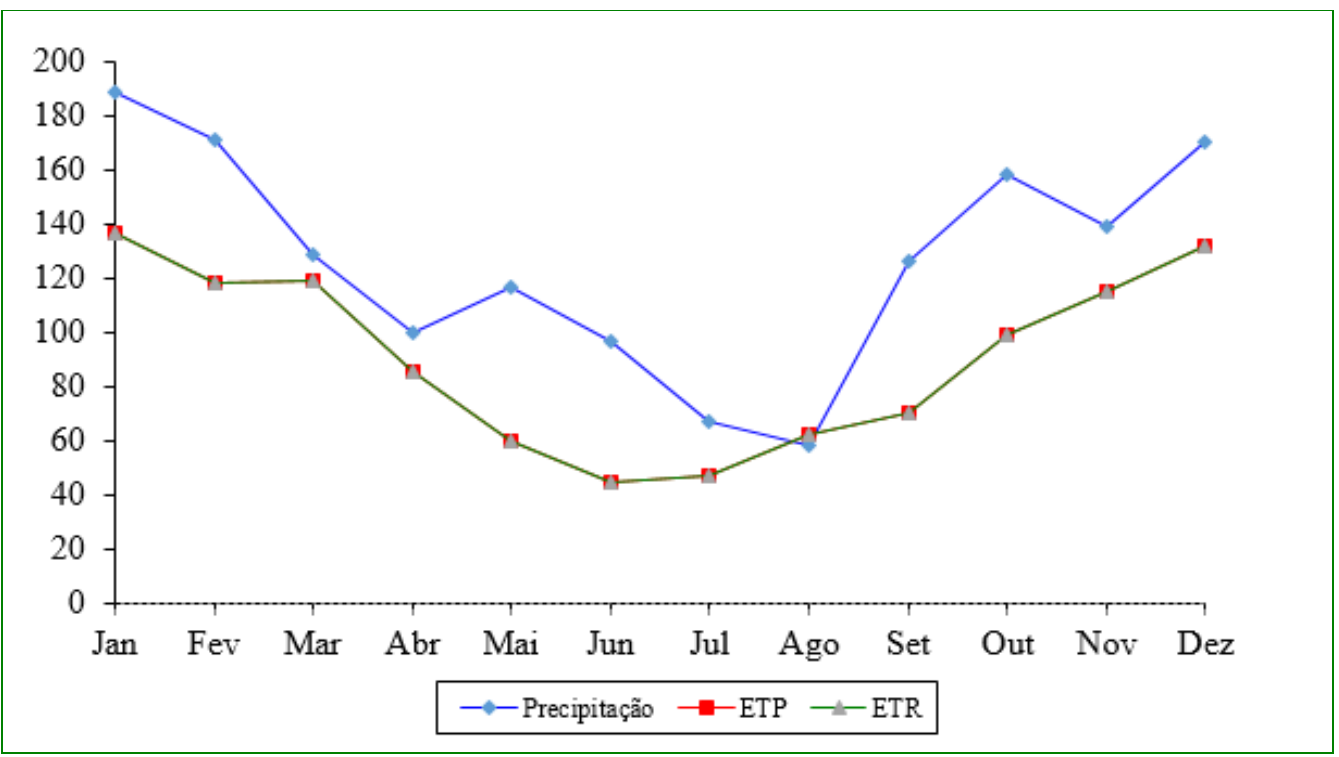

Fonte: Do autor (2021).

De acordo com a Figura 3, o período de deficiência hídrica em Paranavaí fica compreendido no mês de agosto. Essa condição de deficiência está associada a baixa temperatura e precipitação em agosto. Em suma, a região estudada apresenta clima bem definido, com períodos de disponibilidade hídrica em praticamente todo o ano, exceto o mês de agosto. Tal período coincide com plantio de culturas como milho e feijão, devendo ser realizado um planejamento de modo a suprir suas necessidades hídricas (GUIMARÃES et al., 2016). 
Apesar do BHC demonstrar que apenas o mês de agosto possui déficit hídrico, a região do município de Paranavaí é uma das regiões com maiores riscos de estiagens extremas no estado do Paraná (PINTO et al., 2021).

Figura 3 - Deficiência hídrica e excedente hídrico de 1975 à 2018 em Paranavaí, Paraná.

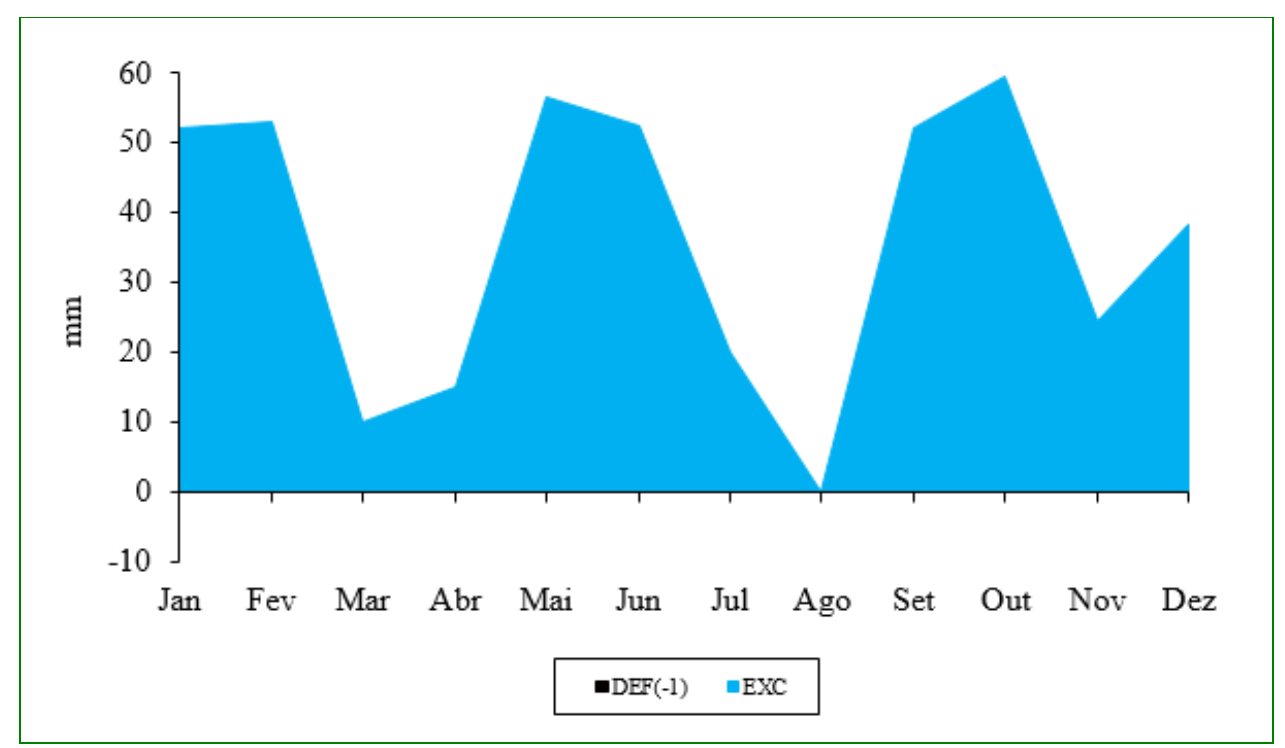

Fonte: Do autor (2021).

Observando-se o BHC para o município de Paranavaí (Figura 4), que apenas no mês de agosto acontece déficit hídrico, com uma deficiência mensal média de $3,7 \mathrm{~mm}$. Após o déficit hídrico em agosto, constata-se que a reposição hídrica ocorre em setembro, onde se inicia o período chuvoso que dura até julho. Portanto, a estimativa do balanço hídrico pelo método adotado, pode ser utilizado para o município de Paranavaí para classificação climática, caracterização hidrológica, estudos do meio ambiente e planejamento agrícola (DOURADO-NETO et al., 2010). 
Figura 4 - Extrato do balanço hídrico normal mensal de Paranavaí, Paraná para o período de 1975 à 2018.

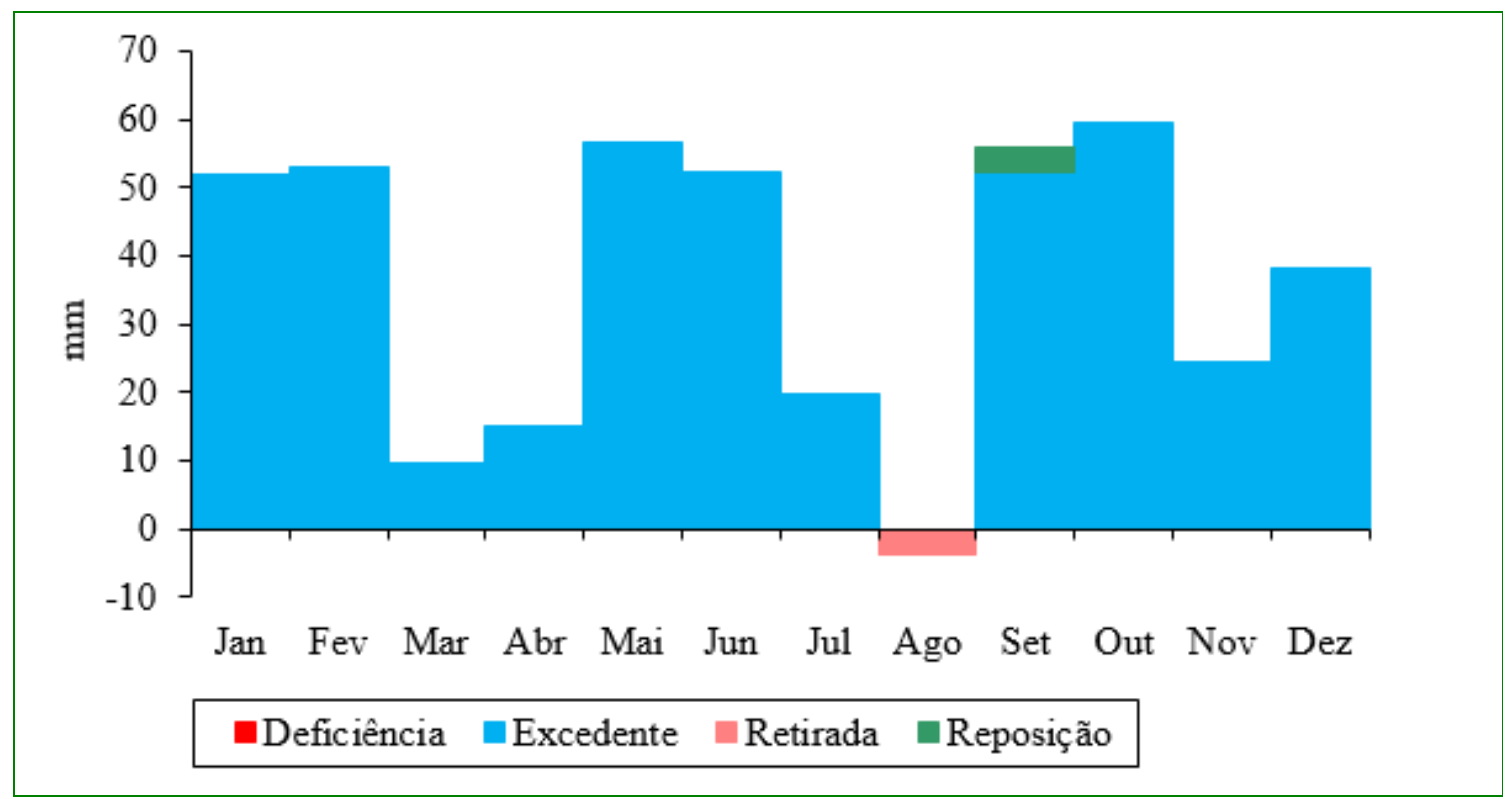

Fonte: Do autor (2021).

A partir dos índices do BHC, foi possível realizar a classificação climática (Tabela 6). Utilizando-se a primeira chave de classificação para obtenção do tipo climático baseado no índice de umidade obteve-se a letra $\mathrm{C}_{2}$ referindo-se a um clima subúmido. Em seguida, por meio da "segunda chave", com base no índice de aridez (la) igual a 0 e índice hídrico (Ih) igual a 39,78, obteve-se a letra r, caracterizando como pequena ou nenhuma deficiência de água. Já a "terceira chave" definida em função da evapotranspiração potencial (ETPanual) de 1090,1 mm, determinou-se o subtipo B'4, que indica clima mesotérmico. Por último, através da "quarta chave", que representa a relação entre a evapotranspiração potencial de verão (ETPv) igual a 506,35 mm obtida pela soma da ETP dos meses (dezembro, janeiro, fevereiro e março) (ROLIM; APARECIDO, 2015), dividida pela evapotranspiração anual (ETPanual), igual a 1090,1 mm, determinando-se o subtipo a'.

Tabela 6 - Classificação climática do município de Paranavaí, Paraná.

\begin{tabular}{ccccc}
\hline Ih (\%) & la (\%) & lu (\%) & ETPanual (mm) & ETPv/ETPanual \\
\hline 39.78 & 0 & 0 & 1090,1 & 46,44 \\
- & $\mathrm{r}$ & $\mathrm{C}_{2}$ & $\mathrm{~B}^{\prime} 4$ & $\mathrm{a}^{\prime}$ \\
\hline
\end{tabular}

Fonte: Do autor (2021).

Assim, a fórmula climática completa é $\mathrm{C}_{2}$ rB'4a', ou seja, o clima para o município de Paranavaí é caracterizado como mesotérmico com pequena ou nenhuma deficiência de água. 
A classificação climática obtida é semelhante a existente pelo método de Koopen (Aw), porém, esta não diferencia os tipos climáticos perdendo em detalhes, enquanto a de Thornthwaite e Mather, além de levar em conta a temperatura, precipitação e evapotranspiração, apresenta em detalhe o período de déficit hídrico anual da localidade (OLIVEIRA, 2019).

Aparecido et al. (2016), obtiveram uma classificação climática distinta a obtida neste trabalho ( $\left.\mathrm{C}_{1} \mathrm{dA} \mathrm{A}^{\prime} \mathrm{a}^{\prime}\right)$ para o município de Paranavaí ao caracterizarem o clima do Paraná com diversos métodos de classificação.

\section{CONCLUSÕES}

O município apresentou tendência climática de um mês de deficiência hídrica (agosto) e onze meses de excedente hídrico (setembro a julho).

Para as principais atividades agrícolas de Paranavaí, recomenda-se a irrigação complementar para períodos de escassez hídrica, já que a precipitação atende as necessidades hídricas das culturas.

Pela classificação climática, o município ficou descrito como $\mathrm{C}_{2}$ rB'4a' representando um clima mesotérmico com pequena ou nenhuma deficiência de água.

\section{REFERÊNCIAS}

APARECIDO, L. E. O.; ROLIM, G. S.; RICHETTI, J.; SOUZA, P. S.; JOHANN, J. A. Köppen, Thornthwaite and Camargo climate classifications for climatic zoning in the state of Paraná, Brazil. Ciência e Agrotecnologia, Lavras, v. 40, n. 4, p. 405-417, 2016. DOI: 10.1590/1413-70542016404003916.

BLAIN, G. C.; BRUNINI, O. Caracterização do regime de evapotranspiração real, em escala decendial, no estado de São Paulo. Revista Brasileira de Meteorologia, São José dos Campos, v. 22, n. 1, p. 75-82, 2007. DOI: 10.1590/S0102-77862007000100008.

DA SILVA, P. L. F.; NASCIMENTO, R. S. Balanço hídrico climatológico e índice de aridez para municípios e microrregião de Guarabira, Paraíba. Revista Brasileira de Engenharia de Biossistemas, Tupã, v. 14, n. 2, p. 125-139, 2020. DOI:

10.18011/bioeng2020v14n2p125-139.

DANTAS, A. A. A.; CARVALHO, L. G.; FERREIRA, E. Classificação e tendência em Lavras, MG. Ciência e Agrotecnologia, Lavras, v. 31, n. 6, p. 1862-1866, 2007. DOI: 10.1590/S1413-70542007000600039. 
DOURADO-NETO, D.; LIER, Q. J. V.; METSELAAR, K.; REICHARDT, K.; NIELSEN, D. R. General procedure to initialize the cyclic soil water balance by the Thornthwaite and Mather method. Scientia Agricola, Piracicaba, v. 67, n. 1, p. 87-95, 2010. DOI: 10.1590/S0103-90162010000100013.

FIDALSKI, J.; TORMENA, C. A.; ALVES, S. J.; AULER, P. A. M. Influência das frações de areia na retenção e disponibilidade de água em solos das formações Caiuá e Paranavaí. Revista Brasileira de Ciência do Solo, Viçosa, v. 37, p. 613-621, 2013. DOI: 10.1590/S0100-06832013000300007.

IAT - INSTITUTO ÁGUA E TERRA. In: Sistema de Informações Hidrológicas, Julho de 2019. Disponível em: www.sih-web.aguasparana.pr.gov.br/sih-web.

IBGE - INSTITUTO BRASILEIRO DE GEOGRAFIA E ESTATÍSTICA. In: Produção Agrícola Municipal (PAM). Outubro de 2021. Disponível em:

www.sidra.ibge.gov.br/pesquisa/pam/tabelas.

MATOS, R. M.; SILVA, P. F.; MEDEIROS, R. M.; SANTOS, B. D. B.; BARROS, A. S.; DANTAS NETO, J.; SABOYA, L. M. F. Balanço hídrico climatológico normal e sequencial para o município de Barbalha - CE. Revista Brasileira de Geografia Física, v. 13, n. 3, p. 973-982, 2020. DOI: 10.26848/rbgf.v13.3.p973-982.

GUIMARÃES, M. J. M.; LOPES, I.; OLDONI, H.; COELHO FILHO, M. A. C. BalançO hídrico para diferentes regimes pluviométricos na região Cruz das Almas-BA. Revista de Ciências Agrárias, Belém, v. 59, n. 3, p. 252-258, 2016. DOI: 10.4322/rca.2205.

OLIVEIRA, J. A. M. Balanço hídrico e classificação climática para o município de Januária-MG. Agropecuária Científica no Semiárido, Patos, v. 15, n. 1, p. 86-91, 2019. DOI: 10.30969/acsa.v15i1.1084.

PARREIRA, A. G. B.; MARASCA, I.; SOLINO, A. J. S.; SANTOS, G. O. Balanço hídrico climatológico para o município de Rio Verde, Goiás. Científic@, Goianésia, v. 6, n. 1, p. 16-33, 2019. DOI: 10.29247/2358-260X.2019v6i1.p26-33.

PASSOS, M. L. V.; ZAMBRZYCKI, G. C.; PEREIRA, R. S. Balanço hídrico e classificação climática para uma determinada região de Chapadinha - MA. Revista Brasileira de Agricultura Irrigada, Fortaleza, v. 10, n. 4, p. 758-766, 2016. DOI:

10.7127/RBAI.V10N400402.

PASSOS, M. L. V.; ZAMBRZYCKI, G. C.; PEREIRA, R. S. Balanço hídrico climatológico e classificação climática para o município de Balsas-MA. Scientia Agraria, Curitiba, v. 18, n. 1, p. 83-89, 2017. DOI: 10.5280/rsa.v18i1.48584.

PINTO, L. F. D.; NITSCHE, P. R.; SILVA, M. A. A.; ALVES, D. S.; CALDANA, N. F. S. Estiagens extremas afetam a agricultura no estado do Paraná, Brasil. Irriga, Botucatu, Edição Especial - Sul, v. 1, n. 2, p. 297-307, 2021. DOI: 10.15809/irriga.2021v1n2p297307. 
ROLIM, G. S.; APARECIDO, L. E. O. Camargo, Köppen and Thornthwaite climate classification systems in defining climatic regions of the state of São Paulo, Brazil. International Journal of Climatology, v. 36, p. 636-643, 2015. DOI: 10.1002/joc.4372.

SALES, R. A.; OLIVEIRA, E. C.; LIMA, M. J. A.; GELCER, E. M.; SANTOS, R. A.; LIMA, C. F. Ajuste dos coeficientes das equações de estimativa da evapotranspiração de referência para São Mateus, ES. Irriga, Botucatu, v. 23, n. 1, p. 154-167, 2018. DOI: 10.15809/irriga.2018v23n1p154.

SILVA, A. O.; MOURA, G. B. A.; KLAR, A. E. Classificação climática de Thornthwaite e sua aplicabilidade agroclimatológica nos diferentes regimes de precipitação em Pernambuco. Irriga, Botucatu, v. 19, n. 1, p. 46-60, 2014. DOI:

10.15809/irriga.2014v19n1p46.

THORNTHWAITE, C. W.; MATHER, J. R. The water balance. Centerton: Drexel Institute of Technology, 1955. (Climatology, v. 8, n. 1).

WORLD METEOROLOGICAL ORGANIZATION - WMO. Calculation of monthly and annual 30-year standard normals: WCDP No. 10, WMO-TD. No 341. Geneva: WMO, 1989. 


\begin{abstract}
Understanding the climatic conditions of the Paranavaí municipality must be considered due to its importance in the national agriculture scenario. In this study, we calculated the climatological water balance (CWB) by performing the climate classification using the method of Thornthwaite and Mather for the municipality of Paranavaí, Paraná. We used temporal series from 1975 to 2018, and we adopted a $100 \mathrm{~mm}$ value for the available water capacity (AWC). Paranavaí presented an annual precipitation average of 1523,8 mm, and $1090,62 \mathrm{~mm}$ of evapotranspiration. The municipality presented only one month with a water deficit (August) and eleven months with a water surplus (September to July). Regarding climate classification, was found C1dA'a's climate, characterized as a mesothermal climate with little or no water déficit.
\end{abstract}

Keywords: Water deficit. Evapotranspiration. Precipitation. Irrigation.

\title{
RESUMEN
}

Se debe considerar el conocimiento de las condiciones climáticas del municipio de Paranavaí por su importancia en el escenario agrícola nacional. En este estudio, calculamos el balance hídrico climatológico $(\mathrm{BHC})$ realizando clasificación climática utilizando el método de Thornthwaite e Mather para el municipio de Paranavaí, Paraná. Usamos series temporales de 1975 a 2018 y adoptamos un valor de $100 \mathrm{~mm}$ para la capacidad de agua disponible (CAD). Paranavaí presentó un promedio anual de precipitación de 1523,8 mm y 1090,62 de evapotranspiración. El municipio presentó solo un mes con déficit hídrico (agosto) y once meses de excedente de agua (septiembre a julio). En cuanto a la clasificación climática, se encontró el clima $\mathrm{C}_{1} \mathrm{dA}$ 'a', caracterizado como un clima mesotermal, com escaso o nulo déficit hídrico.

Palabras-clave: Déficit hidrico. Evapotranspiración. Precipitación. Riego. 


\section{LICENÇA DE USO}

Este é um artigo publicado em acesso aberto (Open Access) sob a licença Creative Commons Atribuição 4.0 Internacional (CC BY 4.0), que permite uso, distribuição e reprodução em qualquer meio, desde que o trabalho original seja corretamente citado. Mais informações em: http://creativecommons.org/licenses/by/4.0

\section{CONFLITO DE INTERESSES}

Os autores declaram que não há conflito de interesses neste trabalho.

\section{CONTRIBUIÇÕES AUTORAIS}

Autor 1: Levantamento de dados, confecção de mapas e gráficos, redação do artigo.

Autor 2: Análise de dados e revisão final.

Autor 3: Redação do artigo e correções.

Autor 4: Análise de dados e revisão final.

Autor 5: Redação do artigo e correções.

\section{FINANCIAMENTO}

O presente trabalho não contou com apoio financeiro.

\section{COMO REFERENCIAR}

LOPES, Allan Remor et al. Balanço hídrico climatológico e classificação climática para o município de Paranavaí, Paraná. Revista Brasileira de Engenharia de Biossistemas (Tupã), v. 15, n. 3, p. 367-380, 2021. DOI:

http://dx.doi.org/10.18011/bioeng2021v15n3p367-380.

\section{RESPONSABILIBADE EDITORIAL}

Prof. Dr. Fernando Ferrari Putti ${ }^{1}$, Prof. Dr. Paulo Sérgio Barbosa dos Santos ${ }^{1}$, Prof. Dr. Eduardo Festozo Vicente ${ }^{1}$ e Prof. Dr. Diogo de Lucca Sartori ${ }^{1}$

1 Universidade Estadual Paulista "Júlio de Mesquita Filho", FCE - Faculdade de Ciências e Engenharia, Tupã, SP, Brasil. 